\title{
Motivation for Choosing Neurology as a Career, among Students of Baghdad Medical College
}

\author{
Zuhair A. Al-Johar' ${ }^{1}$ FIBMS(Neurology), Aqeel Kareem Hatem ${ }^{2}$, \\ FIBMS (Neurology), Hadeel Mohammed Abbas ${ }^{3}$, Hajer Waleed Khaled ${ }^{3}$, Maha Tayib Othman ${ }^{3}$ \\ ${ }^{1}$ Specialist of Neurology, Lecturer of Neurology, Department of Medicine, College of Medicine, University of \\ Baghdad, Baghdad, Iraq, ${ }^{2}$ Consultant Neurologist, Lecturer of Neurology, Department of Medicine, College of \\ Medicine, University of Baghdad, Baghdad, Iraq, ${ }^{3}$ Students at College of Medicine/University of Baghdad, \\ $4^{\text {th }}$ Year/Iraq
}

\begin{abstract}
Purpose: To test the influence of specific factors on motivation for neurology career and especially the effect of taking neurology course, and the effect of gender on them.

Materials and Method: This is an observational cross-sectional, self-administered questionnaire-based study. Structured online surveys were offered to a random sample of 170 final year students of College of MedicinelUniversity of Baghdad from July to September 2018. Assessment included factors that might influence students' choice of neurology as a future career, gender effect on those factors, and especially evaluating the impact of exposure to neurology course on their determination for choosing neurology.
\end{abstract}

Results: A total of 150 students responded to this survey ( $88 \%$ responder rate). About $35.3 \%$ of the participants anticipated that they would chose neurology as their future career. The strongest motivational factors were: passion in neurology $(50 \%)$, role model (38\%), and prestige (36\%). Family and friend's effect and having an illness in the family were less motivating factors. Taking the neurosciences module did motivate the students to choose neurology as their future career $(\mathrm{p}=0.001)$.

Conclusion: Neurology is generally well-regarded by students in our college. There was a statistically significant association between choosing neurology as a future career and the influence of studying neuroscience module. Other significant associations were: will to help neurologically ill patients, having passion in neurology, role model, prestige and family pressure.

Keywords: Neurology, career, medical students, neuro-module, Baghdad.

\section{Introduction}

It is often thought that undergraduates do not make their career preferences until after they have graduated from medical school. However, not only

\section{Corresponding Author:}

\section{Zuhair A. Al-Johar}

Specialist of Neurology, Lecturer of Neurology,

Department of Medicine, College of Medicine,

University of Baghdad, Baghdad, Iraq

e-mail: zaljohar@comed.uobaghdad.edu.iq entrants of medical schools ${ }^{1}$, but even applicants to medical schools, often have strong preferences for or against some medical careers. ${ }^{2-4}$ Neurology, it appears, has a reputation among medical specialties of being particularly hard. Particularly interesting is the concept of "Neurophobia," i.e., perception that neurology is a difficult and complicated subject to understand. ${ }^{5}$

Little is known about the factors that motivate medical students to seek careers in Neuro-medicine. Their choice has been associated with multiple factors, the main ones were intellectual property, helping people with neurological disorders, passion in neurology, role model. Other less chosen factors were prestige, family 
and friends influence, having a neurological illness in the family or among friends, and controllable life style. ${ }^{6,7,8,9}$ Academic exposure to neurology course has a very prominent effect on promoting choosing neurology as a future career whether that course was taken before or after graduation. $6,7,8,10$

Age was seen to affect motivation, older applicants having experience with neurology chose intellectual property over interesting in helping people, while younger ones chose the latter. ${ }^{7}$

Factors that deterred students form choosing neurology were: difficulty of the subject, perception of non-interference, poor quality of life and excessive clinical activities. ${ }^{6,11}$

As regards gender issue, there is an increase in the number of women in neurology in the United State 'US', but even in the US, woman are still facing gender issues when working in neurology, mostly related to underestimation of their skills, and adverse social expectations. $^{12}$

No study on students' selection of neurology as future specialty was conducted before in Iraq.

This study was conducted with the objectives to evaluate the known factors that influence the student's choice of neurology as a future career, the effect of gender on those factors, and to evaluate the impact of exposure to neurology course on their determination of choosing neurology.

\section{Material and Method}

An observational cross sectional survey study was conducted from July to September of 2018 at the College of Medicine, university of Baghdad. Initially 10 students were chosen for a pilot study to assess the accuracy and reliability of the questionnaire, then 170 students were randomly selected from all final $\left(6^{\text {th }}\right)$ year medical students.Consent was taken from the participants and they were informed of the confidential nature of the survey. Participation wasvoluntary and unpaid.

Inclusion criteria: $6^{\text {th }}$ grade [final year] medical students of Baghdad University/College of Medicine.

Exclusion criteria: Students who were unwilling to participate or those who incorrectly/incompletely filled the questionnaire were excluded.
The questionnaire gathered information about: Demographic data: including gender; if the students would choose neurology as a career in the future (yes or no); factors related to choosing neurology as a career (family/friends influence, family/friends doctor, family/ friends with neurological disorder, being influenced by role model, being influenced by prestige, passion in neurology, interest in helping people with neurological disorders, other cause). Questionnaire about the effect of neurology module included: score of neurology course in second academic year, score of neuroscience module in fifth academic year, did neurology courses in second, fifth academic years affect your motivation for choosing neurology as a future career?

Data management and statistical analysis: Initial survey forms for the pilot study were on paper and distributed manually to the students, while the final survey forms included in our study were prepared via Google forms, and were distributed online by using Facebook to all of the respondents. The data was encoded and submitted into SPSS (version 24). All the data were set as categorical variables and the descriptive statistics were presented in frequencies, percentages and 95\% standard deviations, and confidence intervals. Chisquare test [and fisher exact test when applicable] were used to analyze the significance of association between different variables. Unless otherwise noted, statistical significance we set as $\mathrm{p}<0.05$.

\section{Results}

A total of 150 students were included in this study. A responder rate of 0.88 . Male respondents totaled $41(27.3 \%)$ and $109(72.7 \%)$ were females. About $53(35.3 \%)$ of the participants said that they'll choose neuroscience as their future career and the remaining $97(64.7 \%)$ preferred to choose other specialties. Of 109 female participants $40(36.7 \%)$ were going to choose neuroscience compared to $13(31.7 \%)$ of 41 males, a non-statistically significant difference $\left(\chi^{2}=0.3247, \mathrm{p}=\right.$ $0.569)$

Factors related to choosing neurology as a career: The number of students motivated by each factor in the survey and its percentage from the whole sample was as follows: interest in helping people with neurological disorder $125(83 \%)$, passion in neurology $77(51 \%)$, role model 57 (38\%), Prestige 54 (36\%), family/friend with a neurological disorder 49 (33\%), family influence 37 (24.7), presence of family/friend doctor $36(24 \%)$. 
Figure (1) displays the percentages of students choosing each motivational factorfrom the sample of students who were willing to choose neurology as a future career.

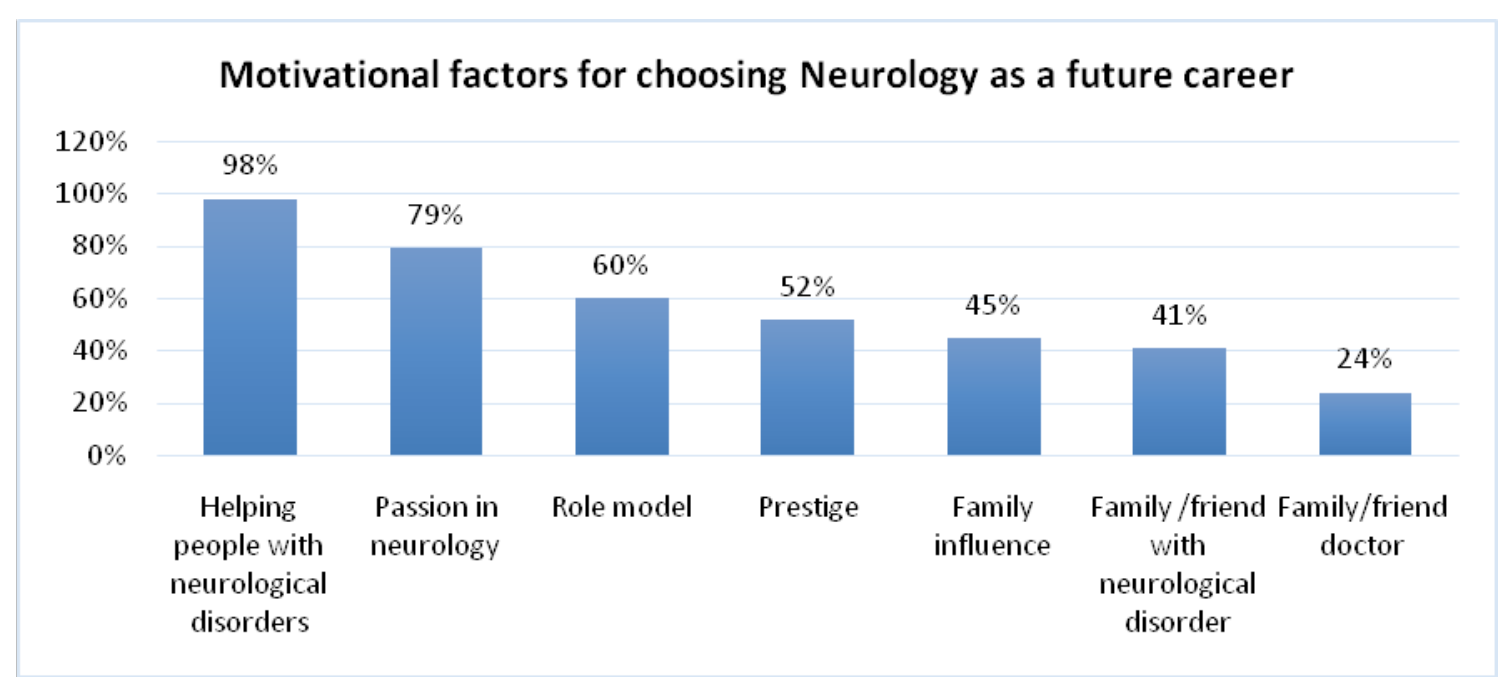

Figure 1: Motivational factors for choosing neurology as a futur career in 53 students who made the choice of neurology as a future career.

Descriptive statistics for motivational factors for choosing neurology per the two choice groups and significance of differences were calculated and are depicted in Table 1.

Table 1: Descriptives and significance of motivational factors for choosing neurology per choice groups

\begin{tabular}{|c|c|c|c|c|c|c|c|c|c|c|}
\hline \multirow{3}{*}{ Motivational factors } & \multicolumn{8}{|c|}{ Did you choose neurology as future career? } & \multirow{2}{*}{\multicolumn{2}{|c|}{ Significance }} \\
\hline & \multicolumn{4}{|c|}{ Yes $(n=53)$} & \multicolumn{4}{|c|}{ No $(n=97)$} & & \\
\hline & $\mathbf{F r}$ & Mean & SD & $95 \% \mathrm{CI}$ & $\mathbf{F r}$ & Mean & SD & $95 \% \mathrm{CI}$ & $\mathbf{X}^{2}$ & $\mathbf{P}$ \\
\hline $\begin{array}{l}\text { Interested in neurology due } \\
\text { to family influence }\end{array}$ & 24 & $\% 45$ & $\% 6.8$ & $31.4 \%-72 \%$ & 13 & $\% 13$ & $3.40 \%$ & $6 \%-\% 20$ & 18.747 & 0.001 \\
\hline $\begin{array}{l}\text { Have family/friend doctor } \\
\text { that motivates you to choose } \\
\text { neurology }\end{array}$ & 13 & $\% 24$ & $5.80 \%$ & $12.4 \%-35.6 \%$ & 23 & $\% 23$ & $\% 4$ & $15 \%-31 \%$ & 0.013 & 0.911 \\
\hline $\begin{array}{l}\text { Have family/friend with } \\
\text { neurological disorder }\end{array}$ & 22 & $\% 41$ & $\% 6$ & $29 \%-53 \%$ & 27 & $\% 27$ & $4.50 \%$ & $18 \%-36 \%$ & 2.914 & 0.088 \\
\hline $\begin{array}{l}\text { Get influenced by role } \\
\text { model }\end{array}$ & 32 & $\% 60$ & $\% 7$ & $46 \%-74 \%$ & 25 & $\% 25$ & $\% 4.4$ & $16 \%-34 \%$ & 17.42 & 0.001 \\
\hline Prestige & 28 & $\% 52$ & $\% 6$ & $24 \%-40 \%$ & 26 & $\% 27$ & $4 \%$ & $17 \%-35 \%$ & 10.076 & 0.002 \\
\hline Havepassion in neurology & 42 & $\% 79$ & $\% 5$ & $68 \%-90 \%$ & 35 & $\% 36$ & $4.80 \%$ & $27 \%-45 \%$ & 25.559 & 0.001 \\
\hline $\begin{array}{l}\text { Interested in helping people } \\
\text { with neurological disorders }\end{array}$ & 52 & $\% 98$ & $\% 1.9$ & $94 \%-100 \%$ & 73 & $\% 75$ & $\% 4$ & $67 \%-83 \%$ & 12.89 & 0.001 \\
\hline
\end{tabular}

The association between gender and the factors that influence the students' choice of Neurology was calculated and presented in Table 2 .

Table 2: Signficance of the effect of gender on motivational factors for choosing neurology as a future career

\begin{tabular}{|c|c|c|c|c|c|c|}
\hline \multirow{2}{*}{ Motivational Factors } & \multicolumn{2}{|c|}{ Male $(n=41)$} & \multicolumn{2}{|c|}{ Female $(n=109)$} & \multirow{2}{*}{$\begin{array}{c}X^{2} \text { test } \\
\text { statistic }\end{array}$} & \multirow{2}{*}{ P-value } \\
\hline & Fr. & $\%$ & Fr. & $\%$ & & \\
\hline Interested in neurology due to family influence & 9 & $22 \%$ & 28 & $26 \%$ & 0.224 & 0.636 \\
\hline Have a family/friend doctor that motivates you to choose neurology & 15 & $37 \%$ & 21 & $19 \%$ & 4.899 & 0.027 \\
\hline
\end{tabular}




\begin{tabular}{|c|c|c|c|c|c|c|}
\hline \multirow{2}{*}{ Motivational Factors } & \multicolumn{2}{|c|}{ Male $(n=41)$} & \multicolumn{2}{|c|}{ Female $(n=109)$} & \multirow{2}{*}{$\begin{array}{c}X^{2} \text { test } \\
\text { statistic }\end{array}$} & \multirow{2}{*}{ P-value } \\
\hline & Fr. & $\%$ & Fr. & $\%$ & & \\
\hline Have a family/friend with neurological disorder & 12 & $29 \%$ & 37 & $34 \%$ & 0.296 & 0.586 \\
\hline Get influenced by role model & 16 & $39 \%$ & 41 & $38 \%$ & 0.025 & 0.874 \\
\hline Prestige & 21 & $51 \%$ & 33 & $30 \%$ & 5.672 & 0.017 \\
\hline Have passion in neurology & 18 & $44 \%$ & 59 & $54 \%$ & 1.247 & 0.264 \\
\hline Interested in helping people with neurological disorders & 34 & $83 \%$ & 91 & $83 \%$ & 0.102 & 0.935 \\
\hline
\end{tabular}

The effect of Neuroscience modules: The distribution of students according to their scores at the end of the second and fifth grade neuroscience modules per choice groups, and significance of their differences, was calculated and depicted in Table 3.

Table 3: Significance of association of students' scores of neurscience modules and choosing neurology as a future career.

\begin{tabular}{|c|c|c|c|c|c|c|c|}
\hline \multirow{3}{*}{\multicolumn{2}{|c|}{ End module scores }} & \multicolumn{4}{|c|}{$\begin{array}{c}\text { Would you choose neurology as your future } \\
\text { career? }\end{array}$} & \multirow{3}{*}{$\begin{array}{l}X^{2} \text { Test } \\
\text { statistic }\end{array}$} & \multirow{3}{*}{ P-value } \\
\hline & & \multicolumn{2}{|c|}{ Yes $(n=53)$} & \multicolumn{2}{|c|}{ No $(n=97)$} & & \\
\hline & & Fr. & $\%$ & Fr. & $\%$ & & \\
\hline \multirow{5}{*}{$\begin{array}{l}\text { Score category in } \\
\text { neuroscience (second } \\
\text { grade) }\end{array}$} & Excellent & 6 & $11.3 \%$ & 14 & $14.4 \%$ & \multirow{5}{*}{2.611} & \multirow{5}{*}{0.625} \\
\hline & Very good & 15 & $28.3 \%$ & 24 & $24.7 \%$ & & \\
\hline & Good & 22 & $41.5 \%$ & 36 & $37.1 \%$ & & \\
\hline & Average & 5 & $9.4 \%$ & 17 & $17.5 \%$ & & \\
\hline & Borderline pass & 5 & $9.4 \%$ & 6 & $6.2 \%$ & & \\
\hline \multirow{5}{*}{$\begin{array}{l}\text { Score category in } \\
\text { neuroscience (fifth } \\
\text { grade) }\end{array}$} & Excellent & 0 & $0.0 \%$ & 5 & $5.2 \%$ & \multirow{5}{*}{7.507} & \multirow{5}{*}{0.115} \\
\hline & Very good & 16 & $30.2 \%$ & 23 & $23.7 \%$ & & \\
\hline & Good & 22 & $41.5 \%$ & 28 & $28.9 \%$ & & \\
\hline & Average & 7 & $13.2 \%$ & 25 & $25.8 \%$ & & \\
\hline & Borderline pass & 8 & $15.1 \%$ & 16 & $16.5 \%$ & & \\
\hline
\end{tabular}

Of males: 5,10,14,10,2 in $2^{\text {nd }}$ grade and 1,6,18,6,10 in $5^{\text {th }}$ grade had excellent, very good, good, average and borderline scores respectively. The respective results for females were $15,29,44,12,9$ in $2^{\text {nd }}$ grade and 4 , $33,32,26,14$ in $5^{\text {th }}$ grade ( $<<0.05$ for both grades).
The student's perception of the motivational effect of taking the neuroscience module of the fifth year, and of both the second and fifth year, on their perceived choice of selecting Neurology as a future career was calculated and depicted in Figure 2. The difference was found be statistically significant $\left(\chi^{2}=62.060, p<0.001\right)$. 


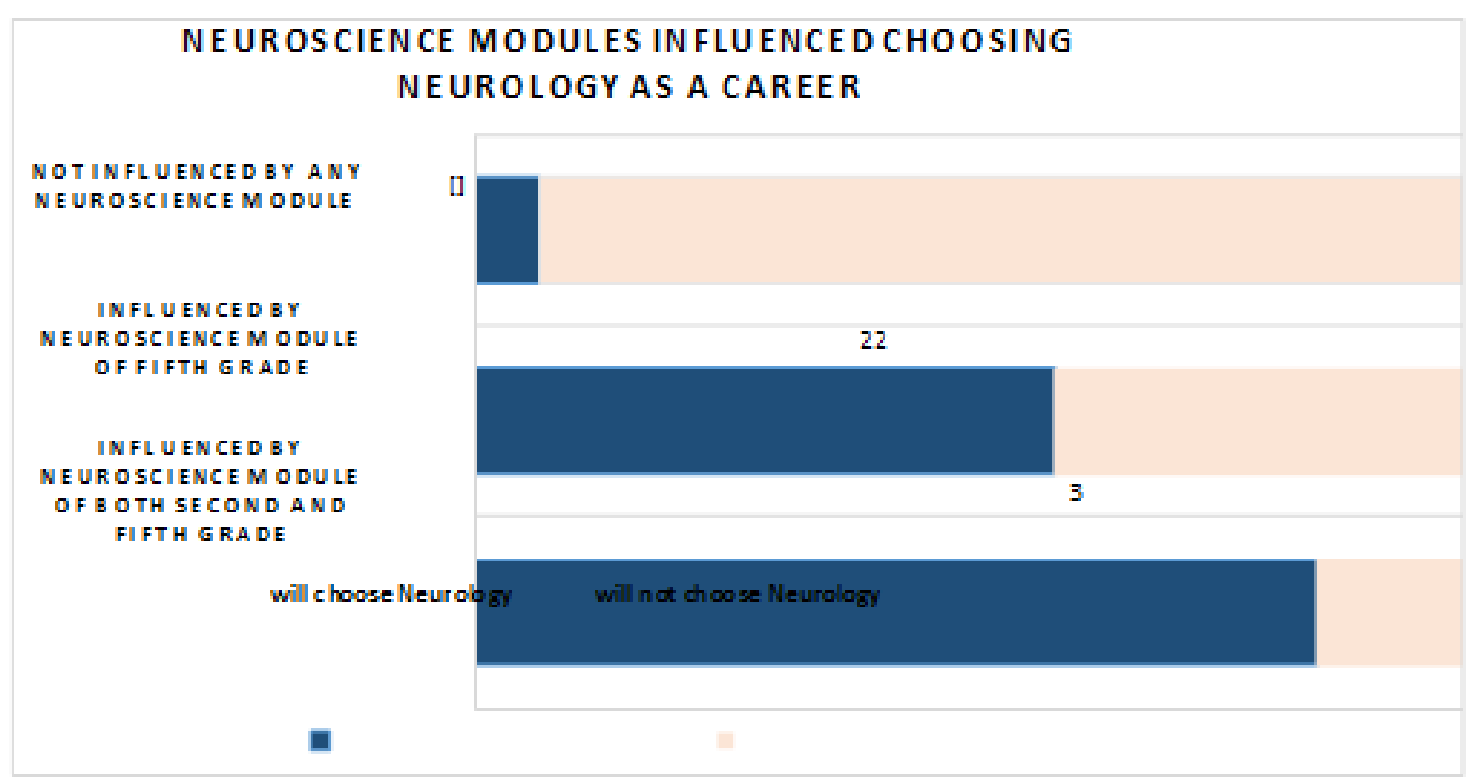

Figure 2: A component bar chart showing the number of students per each influence group and their perceived choices for choosing Neurology as a career.

\section{Discussion}

Neurology was the career of choice for $35.3 \%$ of students in this study, suggesting that neurology is generally well-appreciated by our students. In comparison to Gupta N. etal study ${ }^{6}$ in which only $19 \%$ of students were willing to choose neurology.

The percentage of female students in our college is very high, constituting $54.4 \%$ in a prior study ${ }^{13}$ and around $72.7 \%$ in this study. Therefore gender related motivational issues to neurology must be addressed.

Analyzing the factors that are related to choosing neurology: $24.7 \%$ said that their families had an influence on their interest, whereas Gupta N. et al study showed that only $2 \%$ of the students reported family influence and pressure. ${ }^{6}$ This rather big difference could be due to cultural difference and differences in family involvement in students' life between different societies. There was not gender difference regarding this factor.

For the family/friend neurologist influence, 24\% agreed that having a family/friend neurologist doctor motivated them to pick neurology. After extensive research this was not tested by other studies as a relating factor, although it shows a large effect on students in this study. However this study didn't reveal any significant association between this factor and the will to choose neurology as a future career. However this study did show that males are more prone to be affected by that factor than females $(\mathrm{p}=0.027)$.

Students who have a family/friend with a neurological disorder were $32.7 \%$, this was also not tested by other studies. However this study didn't show any significant association between this factor and choosing neurology as a future career at 0.05 level of significance, however the result was significant at 0.10 level. No gender difference was found in this study.

Having a role model influenced $38 \%$, which is consistent with the findings of Thomas R. which had $37 \%$ influence on the students. ${ }^{8}$ This factor is consistently reported in most studies about motivation in neurology. ${ }^{6,7,8}$ This came here as the third highest factor that motivated students in our sample before prestige and family $\backslash$ friends impact, which largely agrees with earlier studies. ${ }^{6,7,8}$ This equally affected both genders in this study.

Considering neurology as a prestigious job inspired $54(36 \%)$, on the other hand Gupta N. ${ }^{6}$, showed that $18 \%$ considered neurology as a prestige job. This might be because considering neurology as prestige might signal cultural grounds for this difference. In our study this significantly affected males more than females $(\mathrm{p}=0.017)$.

Passion in neurology was shown to affect more 
than half of the students andwithout gender related differences, this agrees with the findings of Gupta N. ${ }^{6}$ in which also about more than half of the students (52 $\%)$ were passionate and interested in neurology as a job. Passion in neurology was one of the commonest factors related to picking neurology among students in this study. Also this agrees with most studies. ${ }^{6,7,8}$

Students who reported having an interest to help people with neurological diseases were $83.3 \%$. Also $82.6 \%$ were interested in helping people with neurological diseases in the study of Albert $\mathrm{D}^{10}$. This agrees with most studies. ${ }^{6,7,8}$ In our study this included all students who would and wouldn't choose neurology as a future career, males and females alike, but surprisingly it was much lower in the group who didn't will to choose neurology as a future career that the difference was significant! Interest in helping people game first before passion in neurology, this agrees with older studies about younger students being motivated by interest in helping people as contrasted with oldermore experienced trainees in neurology which preferred intellectual content. ${ }^{7}$

Meanwhile, for the effect of neuroscience modules and the students' choice of neurology, there was no statistically significant association between students' score and their choice of neurology as a future career, and the same applies to gender effect on scores, this finding agrees with Goni U. et al which also stated having no gender associated difference with different scores. ${ }^{14}$

This study revealed a statistically significant association between choosing neurology as a future career and the influence of neuroscience of $2^{\text {nd }}$ and $5^{\text {th }}$ grade. These findings are supported by all prior studies ${ }^{6,7,8,10}$ all of which reported the effect of undergraduate or postgraduate courses in neurology on future choice of neurology as a career.

\section{Conclusion:}

Neurology is generally well-regarded by students of our college.

There was a statistically significant association between perception of choosing neurology as a future career and factors of: will to help neurologically ill patients, having passion in neurology, role model, prestige, and family pressure, in a descending manner.

There was a statistically significant association between the perception of choosing neurology as a future career and the influence of studying neuroscience module.

Ethical Clearance: The Research Ethical Committee at scientific research by ethical approval of both environmental and health and higher education and scientific research ministries in Iraq

Conflict of Interest: The authors declare that they have no conflict of interest.

Funding: Self-funding

\section{References}

1. Wright B, Scott I, Woloschuk W, Brenneis F, Bradley J. Career choice of new medical students at three Canadian universities: family medicine versus specialty medicine. CMAJ 2004; 170(13): 1920-1924.

2. McManus C,LeffordF, FurnhamF, Shahidi S, Pincus T. Career preference and personality differences in medical school applicants. Psychology, Health and Medicine 1996; 1(3):235-248.

3. Hutt R, Parsons D, Pearson R. The timing of and reasons for doctors' career decisions. Health Trends 1981;13(1):17-20

4. Zeldow B, Preston C, Daugherty R. The decision to enter a medical specialty: timing and stability. Medical Education 1992;26(4):327-332.

5. Jozefowicz R. Neurophobia: the fear of neurology among medical students. Arch Neurol 1994;51(4):328-329.

6. Gupta NB, Khadilkar SV, Bangar SS, Patil TR, Chaudhari CR. Neurology as career option among postgraduate medical students. Ann Indian Acad Neurol 2013;16:478-82

7. Albert DV, Hoyle C, Yin H, McCoyd M, Lukas RV. Why neurology? Factors which influence career choice in neurology. Neurological Research 2016;38(1):10-4.

8. Thomas R, Devine H, Donnelly A, et al. Why neurology? The career choices of current UK neurology trainees. Journal of Neurology, Neurosurgery \& Psychiatry 2015; 86 (11), e4.132-e4

9. Schwartz RW, Jarecky RK, Strodel WE, Haley JV, Young B, Griffen WO Jr. Controllable lifestyle: a new factor in career choice by medical students. Acad Med 1989; 64(10):606-9. 
10. Farrow A, Gordon D, Prodan C. The Effect of a Clerkship Didactic Curriculum on Medical Student Career Choice in Neurology (S6.002). Neurology 2017; 88(16 Supplement):S6.002

11. Roy B, Banerjee I, Sathian B. Neurology as future career - medical student's opinion and factors influenced: A study from Nepal. Neurons 2014, 1(1): 23-27

12. Collins TR. Women in Neurology Should Be Aware of Gender Issues and Work More on Self Promotion, Career Development Coach Says. Neurology Today 2010; 10 (1):16
13. Al-Johar ZA, Ridha AA, Zidan DS, Salih DM. Motivation for Choosing Medicine as a Career, among Students of Baghdad Medical College. Indian J Public Health Res Dev 2019; 10(10): 1286-1291

14. Goni U, wali S, Ali H, Bularafa M. Gender Difference in Students' Academic Performance in Colleges of Education in Borno State, Nigeria: Implications for Counselling. JEP 2015; 6(32): 107-114. 